\title{
Association between the nationality of nurses and safety culture in maternity units of Oman
}

\author{
Waleed Al Nadabi, ${ }^{1}$ Muhammad Faisal ${ }^{1}$ and Mohammed A. Mohammed ${ }^{1}$ \\ ${ }^{1}$ Faculty of Health Studies, University of Bradford, Bradford, United Kingdom (Correspondence to: Waleed Al Nadabi: w.k.a.alnadabi@bradford.ac.uk).
}

\begin{abstract}
Background: Patient safety culture/climate in maternity units has been linked to better safety outcomes. Nurses have a crucial role in patient safety and represent the majority of staff in maternity units. In many countries, nurses are recruited from abroad, bringing their own perceptions of patient safety culture. Nonetheless, little is known about the relationship between perceptions of patient safety culture and nurses' nationality. Understanding this relationship will assist stakeholders in designing a responsive programme to improve patient safety culture.
\end{abstract}

Aims: To investigate the association between nurses' nationality and their perceptions about patient safety culture in maternity units in Ministry of Health hospitals in Oman.

Methods: In 2017, the Safety Attitude Questionnaire (SAQ) was distributed to all staff (892 distributed, 735 returned) in 10 maternity units.

Results: About three-quarters ( $74 \%, 541 / 735)$ of the returned SAQs were completed by nurses, of whom $34 \%$ were non-Omani, $21.8 \%$ were Omani and $44.7 \%$ did not report their nationality (missing). Overall, the mean safety score for non-Omani nurses was significantly higher than for the Omani nurses: 3.9 (SD 1.3) vs 3.6 (SD 1.2) $(P<0.001)$. The mean safety score for stress recognition was significantly lower for non-Omani nurses: 2.8 (SD 1.5) vs 3.2 (SD 1.3) $(P<0.001)$.

Conclusion: Non-Omani nurses have a more positive perception of patient safety culture than Omani nurses except in respect of stress recognition. Decision-makers, directors, and clinicians should consider these differences when designing interventions to improve patient safety culture.

Keywords: patient safety culture, nurses, maternity units, nationality, Oman

Citation: Al Nadabi W; Faisal M; Mohammed MA. Association between the nationality of nurses and safety culture in maternity units of Oman. East Mediterr Health J. 2020;26(5):517-524. https://doi.org/10.26719/2020.26.5.517

Received: 07/06/18; accepted: 28/11/18

Copyright (c) World Health Organization (WHO) 2020. Open Access. Some rights reserved. This work is available under the CC BY-NC-SA 3.o IGO license (https://creativecommons.org/licenses/by-nc-sa/3.o/igo).

\section{Introduction}

Improving staff perceptions about safety culture (or climate) has been associated with improved patient safety and better health outcomes (1). Since nurses form the majority of the workforce in maternity care and have a crucial influence on patient safety, understanding the factors that affect their perceptions will support patient safety improvement projects (2). Variables such as education level, work hours and years of experience have been found to impact nurses' perceptions (2-5). Moreover, in countries which rely heavily on nurses from abroad, with varying cultural and linguistic backgrounds, the perceptions of patient safety may differ between local and international nurses (6).

Despite the increasing number of studies examining safety culture, studies exploring the association between safety culture and nationality/ethnicity are not common (6). Our search of the literature (Tables 1,2) found 7 studies only (6-12); 2 were conducted in Saudi Arabia, 2 in the United States of America (USA) and the rest in Norway, Belgium and Switzerland. Four studies focused on variation among nurses and the remaining studies included other categories of staff. No study focused on a particular unit/department within a hospital. The tools used to examine safety culture in these studies included the Hospital Survey on Patient Safety Culture, the Safety Climate Survey, and the Safety Organizing Scale, but not the Safety Attitudes Questionnaire (SAQ).

A study which examined nurses' perceptions of safety culture in Saudi Arabia found that the nonArabic speaking nurses had a greater positive response compared with the Arabic speaking nurses (7). Ari et al. studied the factors affecting the perception of nurses on safety culture, however, there was no discussion on the association between ethnicity and safety culture (4). In Oman, where the present study was conducted, 2 studies assessed safety culture at the hospital level using the Hospital Survey on Patient Safety Culture, but neither examined the association between respondents' nationality and safety culture $(6,13)$.

This is the first study to investigate the association between the nationality of nurses and their perceptions of safety culture in maternity care units in Ministry of Health hospitals in Oman. The results of this study will inform policy-makers, hospital administrators, researchers and nurse managers on designing and 


\begin{tabular}{ll}
\hline $\begin{array}{l}\text { Table } 1 \text { List of databases, search terms and number of studies screened/included in the systematic search } \\
\text { Item }\end{array}$ & CINAH, Medline, PsycInfo, Embase, ASSIA \\
\hline Databases used & March 2018 \\
Month and year of conducting search & English \\
Language & No limit was used \\
Year of publication & (Safety culture or safety climate) combined with (ethnic* or rac* or nationality or language) \\
Search terms combinations & 302 \\
Total articles found & 206 \\
Screened after removing duplicates & 14 \\
Considered for full text review & 7 \\
Included in the review &
\end{tabular}

planning a more responsive patient safety improvement programme.

\section{Methods}

\section{Design}

The current study is a descriptive cross-sectional study.

\section{Sample and settings}

Oman is a developing country located in the South-Eastern corner of the Arabian Peninsula. The nursing staff is predominantly female and $42 \%$ of nurses working in the Omani Ministry of Health institutions are recruited from countries such as India and the Philippines (14). This study was conducted in all maternity units in Ministry of Health hospitals in Oman. The complete survey targeted a number of staff categories: bedside nurses, midwives, physicians, students and residents who had worked for a minimum of 4 weeks before conducting the study.

\section{The Safety Attitudes Questionnaire}

The English short form of the SAQ (https://med.uth.edu/ chqs/files/2018/05/SAQ-Short-Form-2006.pdf) was used to examine the safety culture in this study. The SAQ was developed by the University of Texas and has 36 questions covering 6 domains: teamwork climate (items 1-6), safety culture (items 7-13), job satisfaction (items 15-19), stress recognition (items 20-23), perception of management (items 24-28), and working conditions (29-32).
Items 14 and 33-36 are not part of the scales above. All 36 questions use a 5-point Likert scale as follows: strongly disagree $=1$; slightly disagree $=2$; neutral = 3; slightly agree $=4$ and strongly agree $=5$ (15). In the original quess tionnaire, items $24-28$ asked staff about their perception of management in the department as well as in the hospital at large, but for this study, results were only kept for the department level. This tool was chosen because it has been tested in different countries, including the USA, the United Kingdom and Norway, and its validity and reliability has been proven (15-17). Cronbach's alpha for the original scale was 0.93 (18), and in our study it was 0.91 . Additionally, the relatively short completion time (15-20 minutes) made the SAQ more acceptable (17).

\section{Survey distribution and collection}

The survey was piloted in January 2017 in one hospital to identify any potential challenges (e.g. low response rate, distribution problems) before conducting it in the remaining hospitals during April-May 2017. The data from the pilot site were included in the final analysis as no change was made to the survey or sample. Heads of the quality departments were met in April 2017 and given the study guideline to standardize the survey distribution and collection in all hospitals. The surveys were copied and coded according to the published guidelines (19).

The surveys were handed out to participants by a quality department staff member during or after their

Table 2 List of references considered for full text review but excluded from the final review

\begin{tabular}{ll}
\hline Study & Reason for exclusion \\
\hline Gabrani et al. http://dx.doi.org/10.1111/jnu.12236 & Measured safety culture but ethnicity/nationality not discussed \\
Groves et al. https://doi.org/10.1111/j.1365-2648.2011.05619.x & $\begin{array}{l}\text { Discussed the theory of safety culture. Not an original study. } \\
\text { Association between safety and ethnicity/nationality/language not discussed }\end{array}$ \\
Hamdan et al. https://doi.org/10.1093/intqhc/mzto07 & $\begin{array}{l}\text { A review not a primary study; association not discussed in the reviewed } \\
\text { studies }\end{array}$ \\
Kagawa-Singer et al. http://dx.doi.org/10.1016/j.soncn.2009.11.008 & $\begin{array}{l}\text { Did not discuss association, just outlined that cultural heterogeneity needs } \\
\text { further analysis }\end{array}$ \\
Alayed et al. https://doi.org/10.1108/IJHCQA-04-2013-0042 & $\begin{array}{l}\text { Safety culture and its association with ethnicity/nationality not discussed; } \\
\text { did discuss the ability of validated tool to detect transcultural variation }\end{array}$ \\
Smith et al. https://doi.org/10.1177/1043659611404423 & Measured safety culture but ethnicity/nationality not discussed
\end{tabular}


morning meeting. The nurse-in-charge collected surveys from the nurses and the quality departments sent all surveys to a central department in the Ministry of Health. Data were then entered by a coordinator working for the principal investigator, who double checked the data for accuracy.

\section{Ethical considerations}

The study was approved by the Research and Ethical Review and Approval committee, Ministry of Health, Oman (MoH/DGPS/CSR/PROPOSAL_APPROVED/2/2017). Participants were given a cover page with the questionnaire explaining that participation was voluntary, confidentiality would be maintained, and information able to identify the person was not requested.

\section{Statistical analysis}

The survey Likert scales were used to measure the mean score for all except 2 of the 36 safety items; these were items 11 and 36, which were appropriately reverse coded as per the guidelines (19). The overall mean scores were calculated by summing the score from all respondents and dividing by the number of responses. Similarly, the mean score for each safety domain was calculated by adding the scores of items for each domain and dividing by the number of responses. To calculate the percentage of positive responses, these responses were regrouped into negative (strongly disagree, slightly disagree), positive (strongly agree, slightly agree) and neutral response (15). This study targeted different staff categories, but this paper focuses on nurses as they represent the majority of the workforce and have a major impact on safety culture.

Data were presented as mean and standard deviation (SD) and proportions. Radar plots were used for data visualization, given their usefulness in presenting health care data (20). The t-test was used to determine the statistically significant difference in mean scores between non-Omani and Omani nurses. We used chi-squared to test for association between variables. Statistical significance was set at $P<0.05$. When nurses' nationality and other variables were not reported (missing), data were considered as a separate category in our analysis. All data cleaning and analysis were conducted using Stata statistical software.

\section{Results}

\section{Survey responses and respondent's characteristics}

Out of the 892 targeted population, a total of 735 (82\%) questionnaires were returned from the 10 hospitals, of which 541 (74\%) were from nurses.

The response rate among non-Omani nurses was higher than that of Omani nurses (33.5\% vs 21.8\%) (Table 3). In all categories of years of experience, the proportion of Omani nurses was higher than the non-Omani nurses except in the $<5$ years category $(33.2 \%$ of non-Omani nurses, $23.7 \%$ of Omani nurses.

\section{Safety scale for safety domains, years of experience and the 36 items}

The non-Omani nurses had a statistically significantly higher overall mean score (3.9) compared with the Omani nurses (3.6) (Table 4). Among both Omani and non-Omani nurses, job satisfaction (4.2) had the highest mean score while stress recognition (3.1) had the lowest score. Non-Omani nurses scored higher for job satisfaction than Omani nurses (4.5 vs 4.0), however, non-Omani nurses had a lower mean score for stress recognition than Omani nurses (2.8 vs 3.2). In 5 out of the 6 safety domains, the non-Omani nurses had significantly higher mean scores compared with the Omani nurses. These differences were all statistically significant $(P<0.001)$ (Table 4).

Non-Omani nurses had significantly higher mean scores across all the categories of experience compared with Omani nurses (Table 4) and a significantly higher mean score across all the 36 safety items except items 20-23, which are part of the stress recognition domain $(P<0.001)$ (Figure 1).

Just $58.5 \%$ of nurses rated safety culture as positive but this was higher among non-Omanis $(66.9 \%)$ compared with Omanis (56.0\%) (Table 5). The proportion of positive responses for all safety domains was $<75 \%$. The domain that attracted the highest positive response was job satisfaction $(72.8 \%)$ followed by safety culture $(62.1 \%)$, while stress recognition had the lowest value (42.8\%). The positive proportion in all safety domains was higher

\begin{tabular}{|c|c|c|c|c|c|c|}
\hline \multirow[t]{2}{*}{ Years of experience } & Omani nurses & $\begin{array}{l}\text { Non-Omani } \\
\text { nurses }\end{array}$ & Missing & All & \multirow[t]{2}{*}{$\chi^{2}$} & \multirow[t]{2}{*}{$P$-value } \\
\hline & No. (\%) & No. (\%) & No. (\%) & No. $(\%)$ & & \\
\hline$<5$ & $28(23.7)$ & $60(33.2)$ & $73(30.2)$ & $161(29.8)$ & \multirow[t]{6}{*}{20.8} & \multirow[t]{6}{*}{0.002} \\
\hline 5-10 & $44(37.3)$ & $60(33.2)$ & $92(38.0)$ & $196(36.2)$ & & \\
\hline $11-20$ & $35(29.7)$ & $51(28.2)$ & $55(22.7)$ & $141(26.1)$ & & \\
\hline$\geq 21$ & $5(4.2)$ & $7(3.9)$ & $12(5.0)$ & $24(4.4)$ & & \\
\hline Missing & $6(5.1)$ & $3(1.7)$ & $10(4.1)$ & $19(3.5)$ & & \\
\hline Total & 118 (21.8) & $181(33.5)$ & $242(44.7)$ & $541(100)$ & & \\
\hline
\end{tabular}




\begin{tabular}{|c|c|c|c|c|c|c|c|c|}
\hline \multirow[t]{4}{*}{ Category } & \multicolumn{8}{|c|}{ Nationality of nurses } \\
\hline & \multicolumn{2}{|c|}{ Omani } & \multicolumn{2}{|c|}{ Non-Omani } & \multicolumn{2}{|c|}{ Missing } & \multicolumn{2}{|c|}{ All } \\
\hline & \multicolumn{8}{|c|}{ Score } \\
\hline & No. & $\begin{array}{c}\text { Mean } \\
\text { (SD) }\end{array}$ & No. & $\begin{array}{c}\text { Mean } \\
\text { (SD) }\end{array}$ & No. & $\begin{array}{l}\text { Mean } \\
\text { (SD) }\end{array}$ & No. & $\begin{array}{c}\text { Mean } \\
\text { (SD) }\end{array}$ \\
\hline Overall & 4094 & $3.6(1.2)$ & 6411 & $3.9(1.3)$ & 8365 & $3.6(1.2)$ & 18870 & $3.7(1.3)$ \\
\hline \multicolumn{9}{|l|}{ Domain } \\
\hline Job satisfaction & 571 & $4.0(1.1)$ & 898 & $4.5(0.9)$ & 1166 & $4.0(1.1)$ & 2635 & $4.2(1.1)$ \\
\hline Perception of management & 550 & $3.5(1.1)$ & 877 & $3.8(1.3)$ & 1152 & $3.5(1.2)$ & 2579 & $3.6(1.2)$ \\
\hline Safety culture & 810 & $3.6(1.1)$ & 1251 & $4.1(1.1)$ & 1629 & $3.6(1.2)$ & 3690 & $3.8(1.2)$ \\
\hline Stress recognition & 451 & $3.2(1.3)$ & 712 & $2.8(1.5)$ & 926 & $3.3(1.4)$ & 2089 & $3.1(1.4)$ \\
\hline Teamwork climate & 691 & $3.7(1.2)$ & 1076 & $4.0(1.2)$ & 1400 & $3.6(1.2)$ & 3167 & $3.8(1.2)$ \\
\hline Work condition & 461 & $3.3(1.2)$ & 714 & $3.8(1.3)$ & 927 & $3.4(1.3)$ & 2102 & $3.5(1.3)$ \\
\hline Missing & 560 & $3.6(1.2)$ & 883 & $3.8(1.2)$ & 1165 & $3.6(1.2)$ & 2608 & $3.7(1.2)$ \\
\hline \multicolumn{9}{|l|}{ Years experience } \\
\hline$<5$ & 955 & $3.6(1.1)$ & 2128 & $3.8(1.2)$ & 2457 & $3.6(1.2)$ & 5540 & $3.7(1.2)$ \\
\hline $5-10$ & 1534 & $3.6(1.1)$ & 2120 & $3.9(1.3)$ & 3231 & $3.5(1.3)$ & 6885 & $3.6(1.3)$ \\
\hline $11-20$ & 1229 & $3.7(1.2)$ & 1819 & $3.9(1.3)$ & 1928 & $3.7(1.3)$ & 4976 & $3.8(1.3)$ \\
\hline$\geq 21$ & 176 & $3.4(1.2)$ & 237 & $3.8(1.4)$ & 424 & $3.7(1.4)$ & 837 & $3.6(1.4)$ \\
\hline Missing & 200 & $3.3(0.9)$ & 107 & $4.1(1.0)$ & 325 & $3.4(1.0)$ & 632 & $3.5(1.0)$ \\
\hline
\end{tabular}

$S D=$ standard deviation .

Figure 1 Radar plot showing the mean scores for each item on the Safety Attitudes Questionnaire among maternity nurses in Oman according to nationality $(P<0.001$ for all categories)

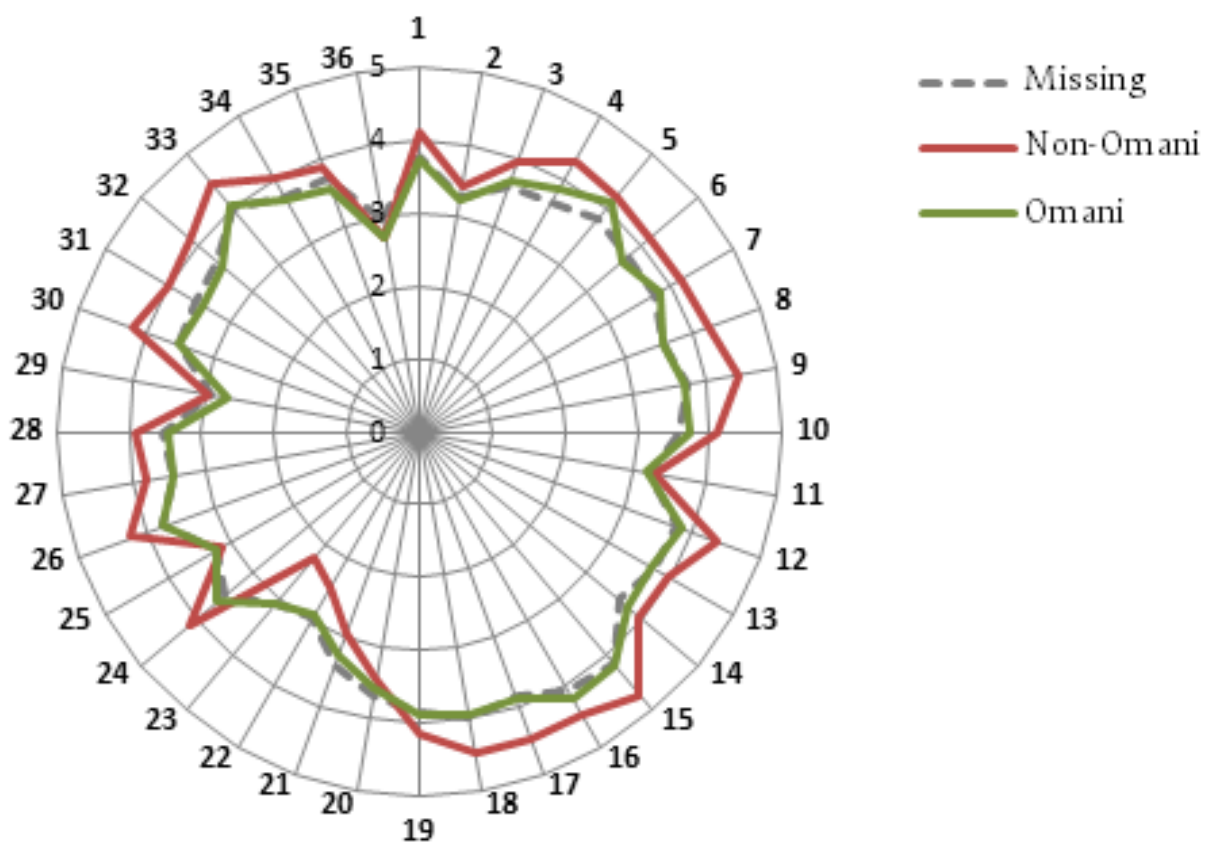




\begin{tabular}{|c|c|c|c|c|}
\hline \multirow[t]{3}{*}{ Domain } & \multicolumn{4}{|c|}{ Nationality of nurses } \\
\hline & Omani & Non-Omani & Missing & All \\
\hline & No. (\%) & No. (\%) & No. (\%) & No. (\%) \\
\hline All domains & 3658 & 5611 & 7502 & 16771 \\
\hline Positive & $2047(56.0)$ & $3755(66.9)$ & $4016(53.5)$ & $9818(58.5)$ \\
\hline Negative & $598(16.3)$ & $895(16.0)$ & $1403(18.7)$ & $2896(17.3)$ \\
\hline Neutral/missing/not applicable & $1013(27.7)$ & $961(17.1)$ & $2083(27.8)$ & $4057(24.2)$ \\
\hline Job satisfaction & 590 & 905 & 1210 & 2705 \\
\hline Positive & $419(71.0)$ & $747(82.5)$ & $803(66.4)$ & $1969(72.8)$ \\
\hline Negative & $48(8.1)$ & $28(3.1)$ & $137(11.3)$ & $213(7.9)$ \\
\hline Neutral/missing/not applicable & $123(20.8)$ & $130(14.4)$ & $270(22.3)$ & $523(19.3)$ \\
\hline Perception of management & 590 & 905 & 1210 & 2705 \\
\hline Positive & $291(49.3)$ & $573(63.3)$ & $582(48.1)$ & $1446(53.5)$ \\
\hline Negative & $79(13.4)$ & $131(14.5)$ & $212(17.5)$ & $422(15.6)$ \\
\hline Neutral/missing/not applicable & $220(37.3)$ & $201(22.2)$ & $416(34.4)$ & $837(30.9)$ \\
\hline Safety culture & 826 & 1267 & 1694 & 3787 \\
\hline Positive & $489(59.2)$ & $931(73.5)$ & $931(55.0)$ & $2351(62.1)$ \\
\hline Negative & $130(15.7)$ & $138(10.9)$ & $297(17.5)$ & $565(14.9)$ \\
\hline Neutral/missing/not applicable & $207(25.1)$ & $198(15.6)$ & $466(27.5)$ & $871(23.0)$ \\
\hline Stress recognition & 472 & 724 & 968 & 2164 \\
\hline Positive & $207(43.9)$ & $275(38.0)$ & $444(45.9)$ & $926(42.8)$ \\
\hline Negative & $122(25.9)$ & $319(44.1)$ & $281(29.0)$ & $722(33.4)$ \\
\hline Neutral/missing/not applicable & $143(30.3)$ & $130(18.0)$ & $243(25.1)$ & $516(23.8)$ \\
\hline Teamwork climate & 708 & 1086 & 1452 & 3246 \\
\hline Positive & $427(60.3)$ & $764(70.4)$ & $802(55.2)$ & $1993(61.4)$ \\
\hline Negative & $113(16.0)$ & $148(13.6)$ & $269(18.5)$ & $530(16.3)$ \\
\hline Neutral/missing/not applicable & $168(23.7)$ & $174(16.0)$ & $381(26.2)$ & $723(22.3)$ \\
\hline Work conditions & 472 & 724 & 968 & 2164 \\
\hline Positive & $214(45 \cdot 3)$ & $465(64.2)$ & $454(46.9)$ & $1133(52.4)$ \\
\hline Negative & $106(22.5)$ & $131(18.1)$ & $207(21.4)$ & $444(20.5)$ \\
\hline Neutral/missing/not applicable & $152(32.2)$ & $128(17.7)$ & $307(31.7)$ & $587(27.1)$ \\
\hline
\end{tabular}

among non-Omani nurses except for stress recognition where $43.9 \%$ of Omani nurses agreed that safety culture was positive compared with $38.0 \%$ of non-Omani nurses.

\section{Discussion}

We found that the overall mean score of patient safety among nurses was not positive (i.e. below 4.0). However, the non-Omani nurses had a positive perception in 3 domains: job satisfaction, safety culture, and teamwork climate while the Omani nurses had a positive score in the job satisfaction domain.

Our findings suggest that there is an association between the nationality of nurses and perceptions of safety culture. Other studies support our findings even though different surveys were used to measure safety culture. For example, a study in Saudi Arabia using the Safety Climate Survey examined the perception of safety culture among nurses from diverse backgrounds (6). There was a significant variation between nurses of different backgrounds, although it was not reported which category had a more positive perception. Another study in Saudi Arabia concluded that the scores of the patient safety culture domains were significantly higher for non-Arabic-speaking nurses for than Arabicspeaking nurses, but without reporting country of origin (7). Similarly, a 2017 study in the USA used the Hospital Survey on Patient Safety Culture to examine the safety culture perceptions among American and immigrant nurses (21). They found that immigrant nurses had a more positive perception. An ethnographic study examining how Korean nurses adapted to USA hospitals found that Korean nurses brought their own culture (beliefs, values, perceptions) with them (22). Although the study was not specific to safety culture, but culture in general, it emphasizes that immigrant nurses do have different perceptions, especially during the first 5 years after immigration.

Our study was a national study focusing on a specific, 
but important, aspect of service, maternity care. It has a good responserateindicating thefeasibility forcontinuous monitoring of safety culture in both maternity and nonmaternity units. It informs stakeholders and researchers on the areas of patient safety that need further attention for each group of nurses (i.e. Omani and non-Omanis). It also emphasises the need to consider the nationality of staff when considering initiatives to improve safety and safety culture.

The main limitation of this study was the high proportion of respondents (45\%) who did not report their nationality. However, other studies had similar issues, such as Almutairi et al. (6) who had $53 \%$ of participants who did not report their nationality. In our study, the perception of safety culture among those who did not report their nationality was very similar to the Omani nurses, which may be an indication that the majority of the unreported nurses were Omani. However, this could not be confirmed in our study. Another limitation, as is the case with other similar studies, was that the reasons for the variations between nationalities could not be explained by cross sectional studies. The greater opportunity for training and exposure might represent a potential explanation for the lower score among the non-Omani nurses with regard to stress recognition. However, further studies will be needed to examine the reasons for these variations.

\section{Conclusion}

The nationality of nurses has an influence on their perception of safety culture. Stress recognition is one safety domain that needs attention from various stakeholders, with special attention on the non-Omani nurses. Decision-makers, executive directors, and clinicians need to consider these differences in perception when designing any interventions to improve safety culture (e.g. training programme, awareness events and orientation plans). Future studies are needed to explain the reasons for the variation of perception between Omani and non-Omani staff with measures to ensure lower rates of missing data.

Funding: This study is part of a PhD study that was funded by the Ministry of Health in Oman.

Competing interests: None declared.

\section{Lien entre la nationalité des personnels infirmiers et la culture de sécurité dans les services de maternité d'Oman}

\section{Résumé}

Contexte : Un lien a été établi entre la culture/le climat de sécurité des patients dans les services de maternité et de meilleurs résultats sur le plan de la sécurité. Les infirmiers(ères) jouent un rôle crucial dans la sécurité des patients et représentent la majorité du personnel des services de maternité. Dans de nombreux pays, les personnels infirmiers sont recrutés à l'étranger et apportent leurs propres perceptions de la culture de la sécurité des patients. Néanmoins, le lien entre les perceptions de la culture de la sécurité des patients et la nationalité des personnels infirmiers est mal connu. Comprendre ce lien aidera les parties prenantes à concevoir un programme pertinent pour améliorer la culture de sécurité des patients.

Objectifs : La présente étude visait à examiner le lien entre la nationalité des personnels infirmiers et leurs perceptions de la culture de la sécurité des patients dans les services de maternité des hôpitaux du ministère de la Santé à Oman.

Méthodes : En 2017, le «Safety attitudes Questionnaire » (SAQ) a été distribué à l'ensemble du personnel de dix services de maternité (892 questionnaires distribués, 735 questionnaires retournés).

Résultats : Près des trois quarts (74\%,541/735) des questionnaires SAQ retournés ont été remplis par des infirmiers(ères), parmi lesquel(le)s $34 \%$ n'étaient pas omanais(es), 21,8\% étaient omanais(es) et 44,7\% n'avaient pas indiqué leur nationalité (manquante). Globalement, le score de sécurité moyen pour les personnels infirmiers non omanais était beaucoup plus élevé que pour ceux qui étaient omanais : 3,9 (E.T. 1,3) contre 3,6 (E.T. 1,2) $(p<0,001)$. Le score de sécurité moyen concernant la reconnaissance du stress était beaucoup moins élevé pour les personnels infirmiers non omanais : 2,8 (E.T. 1,5) contre 3,2 (E.T. 1,3) $(p<0,001)$.

Conclusion : Les personnels infirmiers non omanais ont une perception plus positive de la culture de la sécurité des patients que les ceux qui sont de nationalité omanaise, excepté pour la reconnaissance du stress. Les décideurs, les directeurs et les cliniciens devraient prendre en compte ces différences pour concevoir des interventions visant à améliorer la culture de la sécurité des patients. 


$$
\text { الارتباط بين جنسية طو اقم التمريض وبين ثقافة السلامة في وحدات الأمومة في عُمان }
$$

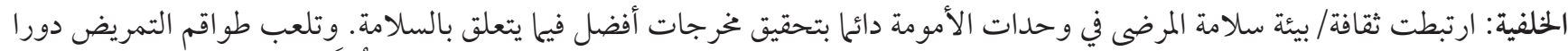

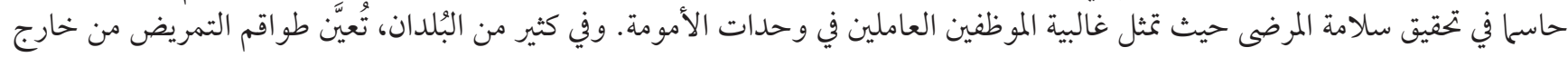

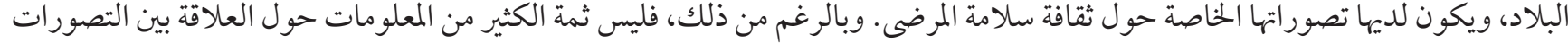

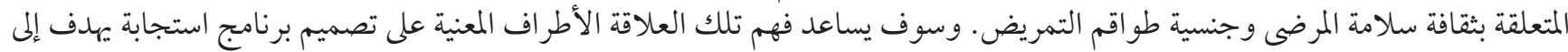
تحسين ثقافة سلامة المرضى.

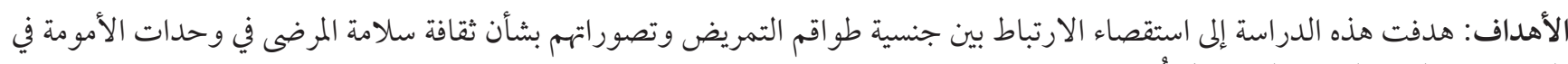
المستشفيات التابعة لوزارة الصحة فذهة في عُمان.

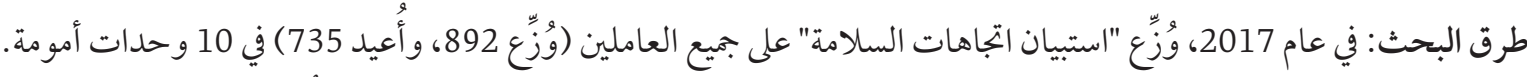

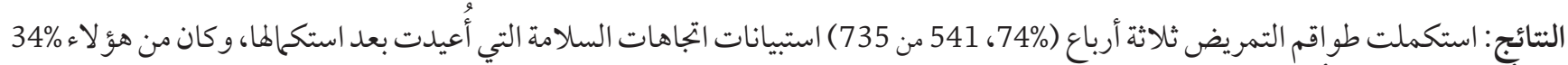

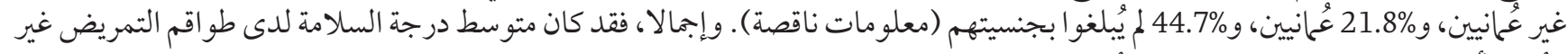

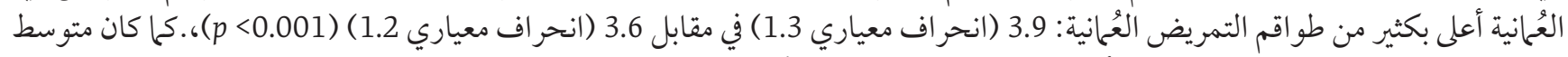

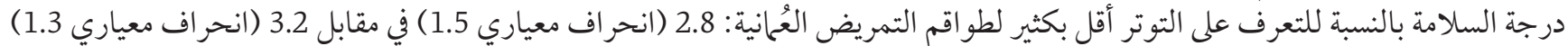

.$(p<0.001)$

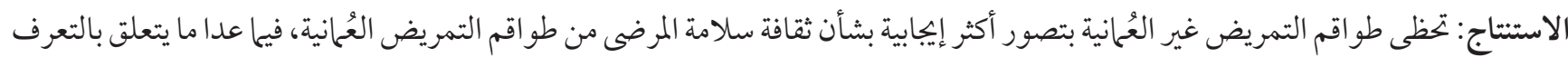

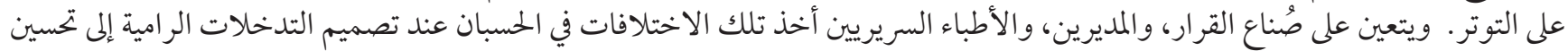
ثقافة سلامة المرضى.

\section{References}

1. DiCuccio $\mathrm{MH}$. The relationship between patient safety culture and patient outcomes: a systematic review. J Patient Saf. 2015;11(3):135-42. https://doi.org/10.1097/PTS.0000000000000058

2. Ridelberg M, Roback K, Nilsen P. Facilitators and barriers influencing patient safety in Swedish hospitals: a qualitative study of nurses' perceptions. BMC Nurs. 2014;13:23. http://dx.doi.org/10.1186/1472-6955-13-23

3. Bodur S, Filiz E. A survey on patient safety culture in primary healthcare services in Turkey. Int J Qual Health Care. 2009;21(5):348-55. https://doi.org/10.1093/intqhc/mzp035

4. Ari M, L. WS, A. AOB. Factors affecting nurses' perceptions of patient safety. Int J Health Care Qual Assur. 2011;24(4):274-83. https://doi.org/10.1108/09526861111125589

5. Cox S, Flin R. Safety culture: philosopher's stone or man of straw? Work \& Stress. 1998;12(3):189-201. https://doi. org/10.1080/02678379808256861

6. Almutairi AF, Gardner G, McCarthy A. Perceptions of clinical safety climate of the multicultural nursing workforce in Saudi Arabia: a cross-sectional survey. Collegian. 2013;20(3):187-94. https://doi.org/10.1016/j.colegn.2012.08.002

7. Aboshaiqah AE. Patients safety culture: a baseline assessment of nurses' perceptions in a Saudi Arabia hospital. Detroit: Wayne State University, 2010 (https://digitalcommons.wayne.edu/oa_dissertations/71, accessed 12 March 2018).

8. Ausserhofer D, Schubert M, Engberg S, Blegen M, De G, Schwendimann R. Nurse-reported patient safety climate in Swiss hospitals: a descriptive-explorative substudy of the Swiss RN4CAST study. Swiss Med Wkly. 2012;142:w13501-w01. https://doi. org/10.4414/smw.2012.13501

9. Bergs CJ. Perceived barriers to quality improvement and reduced medical error: A quantitative study. Phoenix, Arizona: University of Phoenix; 2015 (http://search.ebscohost.com/login.aspx?direct=true\&db=psyh\&AN=2015-99200-190\&site=ehost-live, accessed 12 April 2018).

10. Kim LY. The effects of simulation-based TeamSTEPPS interprofessional communication and teamwork training on patient and provider outcomes. Los Angeles: University of California; 2014 (http://search.ebscohost.com/login.aspx?direct=true\&d$\mathrm{b}=$ rzh\&AN=109774748\&site=ehost-live, accessed 12 April 2018).

11. Skjeggestad E, Norvoll R, Sandal GM, Gulbrandsen P. How do international medical graduates and colleagues perceive and deal with difficulties in everyday collaboration? A qualitative study. Scand J Public Health. 2017;45(4):428-35. https://doi. org/10.1177/1403494817698286

12. Vlayen A, Schrooten W, Wami W, Aerts M, Barrado LG, Claes N, et al. Variability of patient safety culture in Belgian acute hospitals. J Patient Saf. 2015;11(2):110-21. doi:10.1097/PTS.obo13e31829c74a3 
13. Al-Mandhari A, Al-Zakwani I, Al-Kindi M, Tawilah J, Dorvlo AS, Al-Adawi S. Patient safety culture assessment in Oman. Oman Med J. 2014;29(4):264-70. doi:10.5001/omj.2014.70

14. Annual health report. Muscat: Ministry of Health; 2015 (https://www.moh.gov.om/en/web/statistics/annual-reports, accessed 1 March 2018).

15. Sexton JB, Helmreich RL, Neilands TB, Rowan K, Vella K, Boyden J, et al. The Safety Attitudes Questionnaire: psychometric properties, benchmarking data, and emerging research. BMC Health Serv Res. 2006;6:44-44. https://doi.org/10.1186/1472-6963-6-44

16. Bondevik GT, Hofoss D, Hansen EH, Deilkås ECT. The safety attitudes questionnaire - ambulatory version: psychometric properties of the Norwegian translated version for the primary care setting. BMC Health Serv Res. 2014;14(1):139. https://doi. org/10.1186/1472-6963-14-139

17. Deilkås ET, Hofoss D. Psychometric properties of the Norwegian version of the Safety Attitudes Questionnaire (SAQ), Generic version (Short Form 2006). BMC Health Serv Res. 2008;8(1):191. https://doi.org/10.1186/1472-6963-8-191

18. Raftopoulos V, Savva N, Papadopoulou M. Safety culture in the maternity units: a census survey using the Safety Attitudes Questionnaire. BMC Health Serv Res. 2011;11(1):238. doi:10.1186/1472-6963-11-238

19. Sexton JB, Thomas, E.J. and Grillo, S.P. The Safety Attitudes Questionnaire (SAQ) Guidelines for Administration. Houston: University of Texas Center of Excellence for Patient Safety Research and Practice; 2003 (Technical report 03-022003; http://www. ibrarian.net/navon/page.jsp?paperid=15726389\&searchTerm=saq, accessed 19 November 2018).

20. Saary MJ. Radar plots: a useful way for presenting multivariate health care data. J Clin Epidemiol. 2008;61(4):311-17. https://doi. org/10.1016/j.jclinepi.2007.04.021

21. Wagner LM, Brush BL, Castle NG, Engberg JB, Capezuti EA. Nursing home patient safety culture perceptions among US and immigrant nurses. J Patient Saf. 2017 November;[Epub ahead of print]. doi:10.1097/PTS.0000000000000271

22. Yi M, Jezewski MA. Korean nurses' adjustment to hospitals in the United States of America. Journal of advanced nursing. 2000;32(3):721-9. https://doi.org/10.1046/j.1365-2648.2000.01533.x 